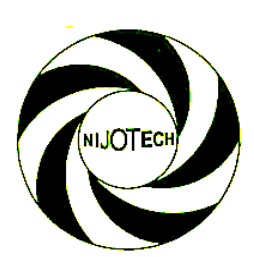

Nigerian Journal of Technology (NIJOTECH)

Vol. 38, No. 3, July 2019, pp. 763 - 768

Copyright@ Faculty of Engineering, University of Nigeria, Nsukka,

Print ISSN: 0331-8443, Electronic ISSN: 2467-8821

www.nijotech.com

http://dx.doi.org/10.4314/njt.v38i3.31

\title{
AN ELECTRONIC BIRTH RECORD MANAGEMENT SYSTEM FOR NIGERIA
}

\author{
F. O. Oliha ${ }^{1, *}$, E. P. Ebietomere ${ }^{2}$ and G. O. Ekuobase ${ }^{3}$

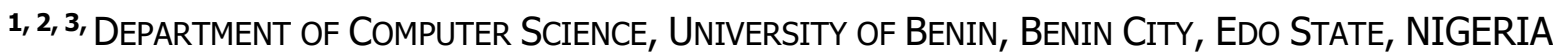 \\ E-mail addresses: ${ }^{1}$ oliha_festus@uniben.edu; ${ }^{2}$ princewill.ebietomere@uniben.edu, \\ 3 godspower.ekuobase@uniben.edu
}

\begin{abstract}
Verifying a citizen's birth information is predominant/y weighted with rigorous processes due to the multitude of birth registration centres and the method of birth registration and archiving its records are operationally manual within the nation. Consequently, this approach is systematically prone to destruction, falsification, alteration, or duplication of birth records and thus, this paper proposed and developed an electronic system for birth registration and record management. It adopted the system analysis and design (SAD) methodology suitably for its designs and implementation. The dataflow diagram (DFD) was adopted for its design while its implementation involved several client and server side development tools: Hypertext Markup Language (HTML), Java Script and Cascading Style Sheet (CSS), Hypertext Pre-Processor (PHP) and My Structured Query Language (MySQL). The resultant prototype system was tested and evaluated entirely, and it demonstrated the capability of birth registration, its records management, and also checking its associated challenges - verification, retrieval, duplications, etc. On full deployment, it will curb the rampart falsification of birth information in Nigeria.
\end{abstract}

Keywords: Civil birth registration, Birth information, Birth certificate, birth falsification.

\section{INTRODUCTION}

In every country, civil registration provides the demographic data used by governments to track the size, differentials and trends of their population. An effective civil registration system provides accurate population data for public resource allocation and planning $[1,2]$. Birth registration is often the basis of birth certificate and other civil records and serves as vital statistics for purpose of planning, resource allocation and immigration [2 - 6]. A birth certificate is a legal document that serves as proof of identity and age [7]. The issuance of birth certificate is a key to certain rights and privileges in every society - often used as "pre-requisite" document to obtain driver licenses, passports, national identity cards, social security cards, job placement and migration documents [8]. This importance attached to birth certificates has exposed it to forgery or falsification [9].
Nigeria presently operates a centralized Civil Registration and Vital Statistics (CRVS) system with no effective means of checking counterfeit birth certificates or conflicting birth records. Detecting counterfeit birth certificates or conflicting birth records in Nigeria is presently almost not possible due to the multitude of birth registration centres with varying certificate appearances, textures and signatures. The implication of such birth registration system is the unfortunate reliance on inaccurate data for national resource allocation, planning, and immigration control [9]. This emphasizes the need for electronic birth record management system in Nigeria.

Electronic birth record management systems are already operational in some developing countries; for example, Indian (since 2003) and Bangladesh (since 2009) and these have really improved their country's vital demographic statistical archives and efficiently checked falsification of birth records $[6,10]$. Consequently, this paper developed an electronic birth

\footnotetext{
* Corresponding author's tel.: +234-818-166-4989
} 
registration system with a view to manage birth records across the multitudes of registration centres in Nigeria. In addendum, it provides a digital repository of birth information to help check some of the bottlenecks associated with birth certificates at the CRVS system.

\section{METHODOLOGY}

\subsection{System's Investigation and Analysis}

The SAD research methodology was adopted. The analysis of the existing birth registration system was done by structured interview of some of its key implementers at the National Population Commission (NPC). These key implementers include Registrars, Deputy Registrars, Deputy Chief Registrars and staff of the Vital Statistics Department of NPC. NPC is the sole organization mandated to establish and maintain a continuous and compulsory CRVS system in Nigeria [11]. The findings from interviews were as follows:

i. Birth registration and birth record
management is manual;
ii. Third parties (e.g. schools, hospitals, immigration officers, etc.) have no means of direct verification of birth information;

iii. Individual birth information verification (retrieval) is grossly inefficient, unreliable and expensive;

iv. No means of checking duplicate birth registration/records of individuals;

v. Birth records were prone to alteration, theft, destruction or disappearance.
These challenges call for the digitization of the Nigerian CRVS system. The authors however, noted the use of a system known as Rapid SMS by the NPC for monitoring registrars and statistical records of births in every registration centre. This system is the only digital tool used by NPC, where every registrar has a unique identification number and reports the number of birth registration cases every week and the statistical reports are updated on the Rapid SMS dashboard which is accessible over the web. The Rapid SMS could only help aggregate summary of birth reports in registration centres with consistent patterns of irregular reporting or non-reporting in some registration centres [12]. The Rapid SMS system therefore does not in any way undermine the call for the digitization of the Nigeria CRVS system.

In Consequent, a framework was proposed for civil birth registration and record management in Nigeria capable of tackling the aforementioned challenges of the present CRVS system in Nigeria.

\subsection{The Proposed Framework}

The framework depicted in Figure 1 is an abstraction of a cybernated system with a digital repository of birth related records in distributed data servers to aid availability and reliability of services. It consists of two dashboards to handle both the managerial activities and the technological services. The client dashboard consists of the user's entity, processes and activities while on the server dashboard are maintenance panel and disparate database servers.

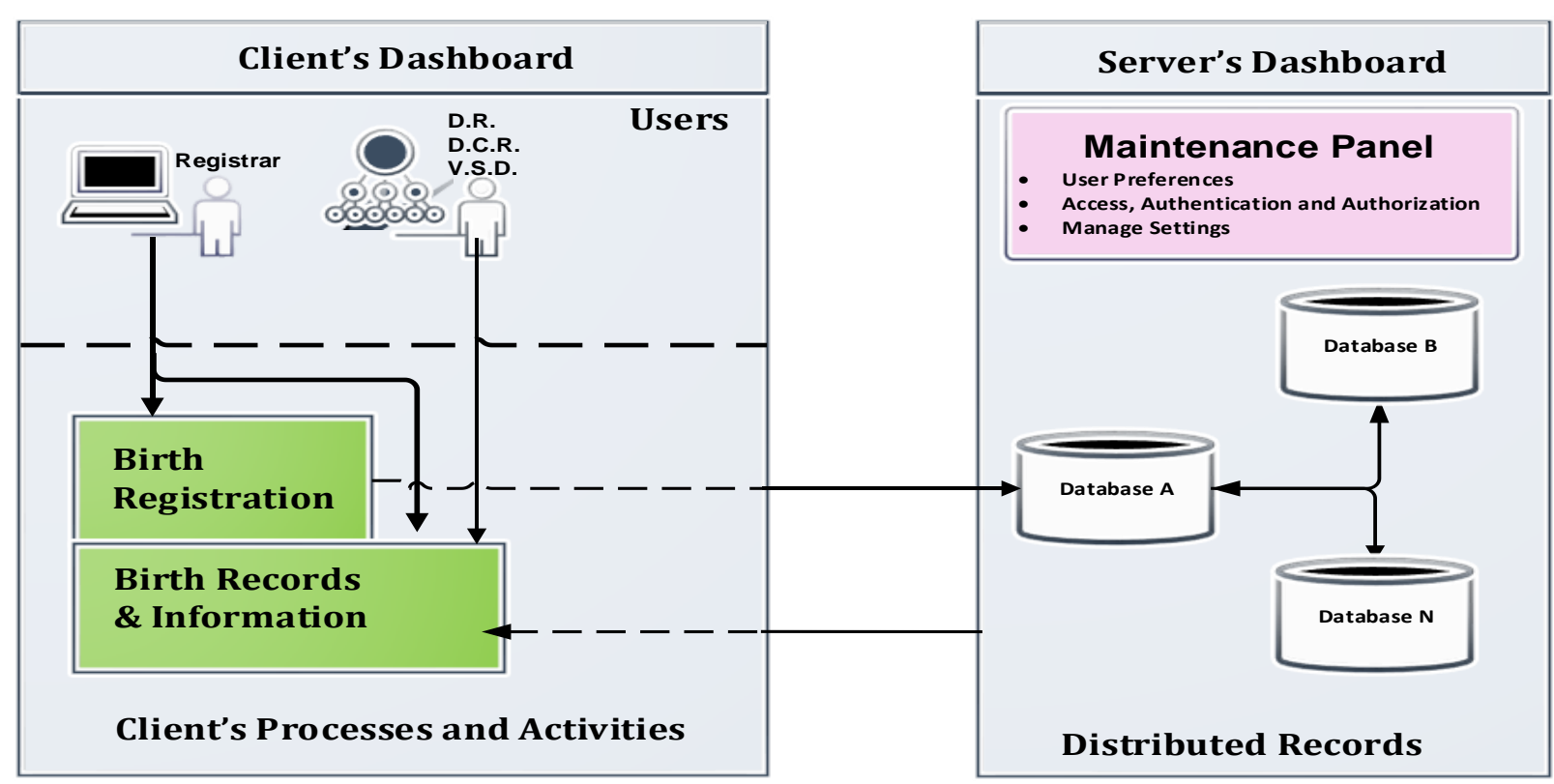

Figure 1: A Framework for Electronic Civil Birth Registration and Records System 
The framework is a two-tier architecture - where processes and functions of the system can be accessed by users (Registrar, Deputy Registrar (DR), Deputy Chief Registrar (DCR) and the Vital Statistics Department (VSD)) through a web browser which gives user access to the client dashboard for interactions with the system. Information from such interactions are deposited and retrieved from the database server at the back end. This will aid real time verification and retrieval of birth information by all and sundry. A reliable, secured and efficient processing and management of Nigerian civil birth information is also guaranteed.

\subsection{System's Design}

The proposed system being an information system was designed using DFD, as depicted in Figure2 and Figure3, in order to express its functionality (processes) and information flow. It was noted by Oliha [13] that DFD is very useful for describing processes and information flow in systems. A brief description of DFD notations can be seen in [14]. Figure 2 captures among others, the proposed system's core functionalities. It describes the proposed system, how it will be accessed and how its components are operationally organized.

Figure 3 represents the data flow diagram for the birth registration and record management process of the system. It shows how inputs are accepted and then processed to generate results for different task such as verifications, authentication and validation. The search process facilitates checks of record existence and allows verification of the claimed birth information.

\subsection{System's Development}

In the development of the prototype civil system, the Sublime Text Integrated Development Environment (IDE) was employed - a text development environment for building scripts files such as PHP and markup files such as HTML. Sublime Text IDE also allows developers to design dynamic web pages and preview websites in locally installed web browsers. Bootstrap was used as a framework for building $\mathrm{CSS} / \mathrm{HTML}$ layout library in making the system attractive, while JavaScript was used to build the system's interactive interface and forms validation. XAMPP (Cross-Platform (X), Apache (A), MySQL (M), PHP (P) and Perl (P)); was used as a local server to test run the system with a structured query language, MySQL for database management. XAMPP is a lightweight Apache distributed application that makes it extremely easy for developers to create a local web server for testing purposes. The system was populated with 50 fictitious birth registration data.

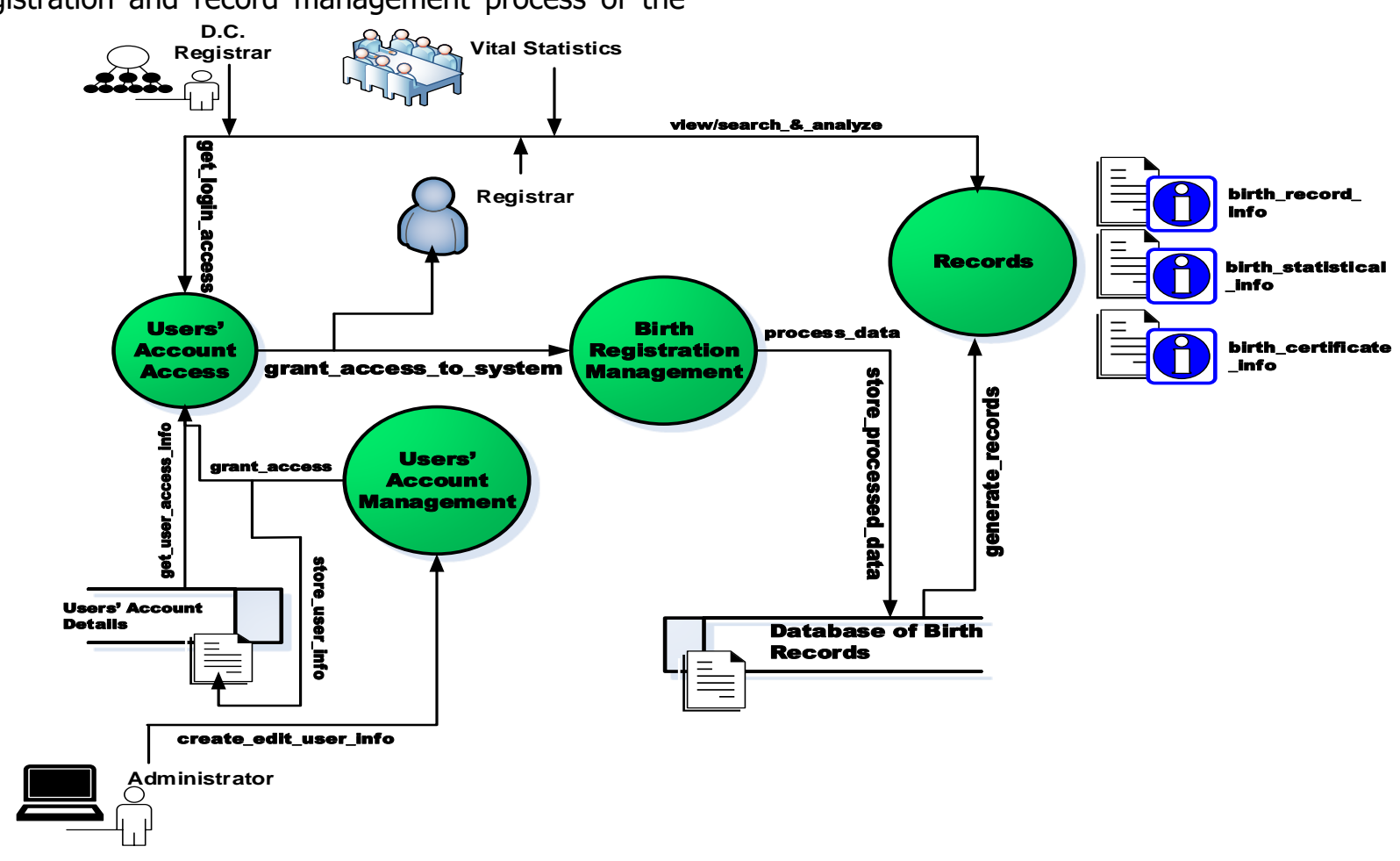

Figure 2: A Level-1 Core of Proposed System DFD 


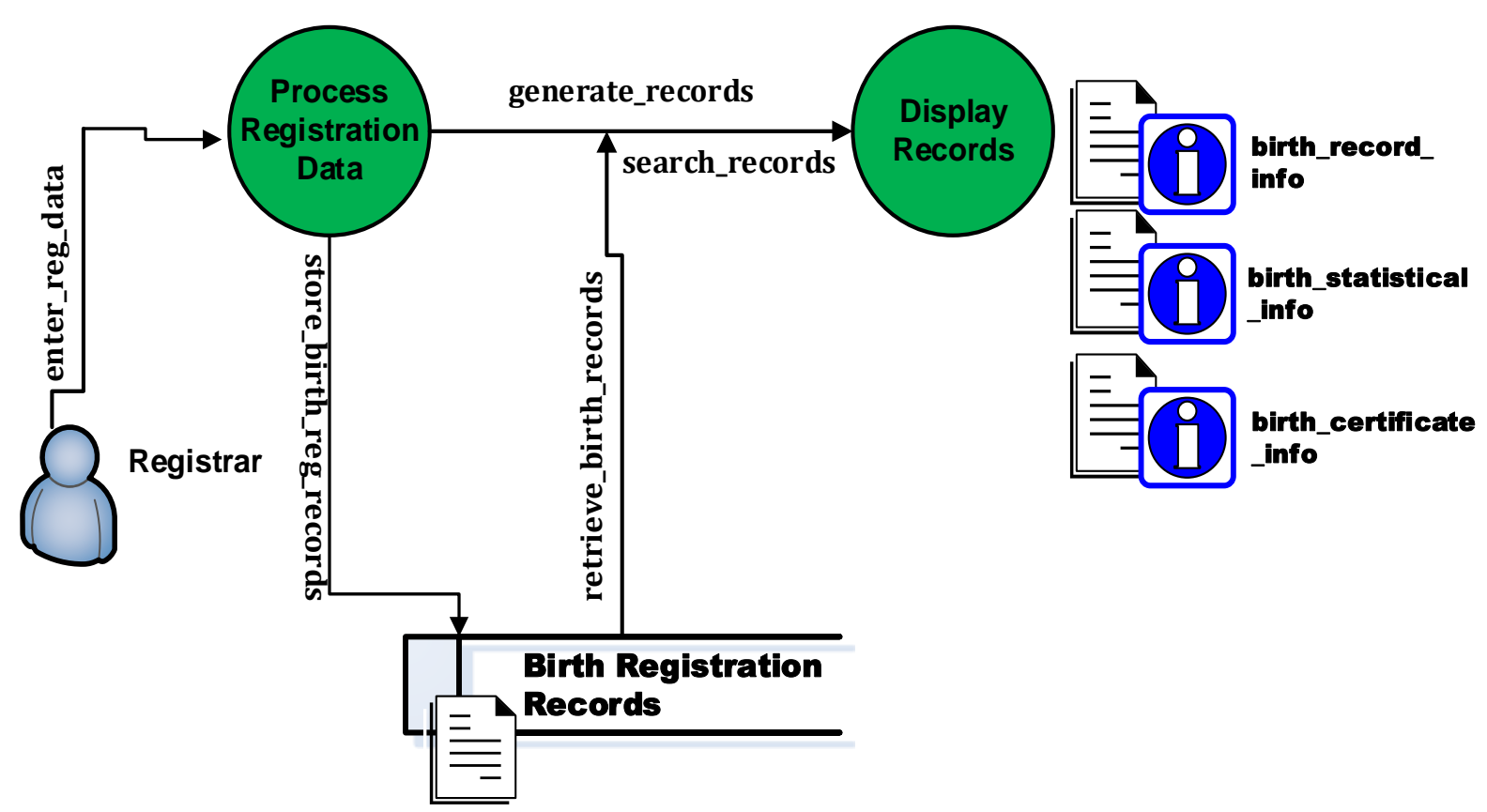

Figure 3: A level - 2 Birth Registration and Record Management DFD

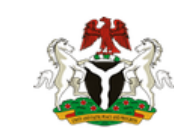

FEDERAL REPUBLIC OF NIGERIA

NATIONAL POPULATION COMMISSION

e-Birth Record Management System (eBiRMS)

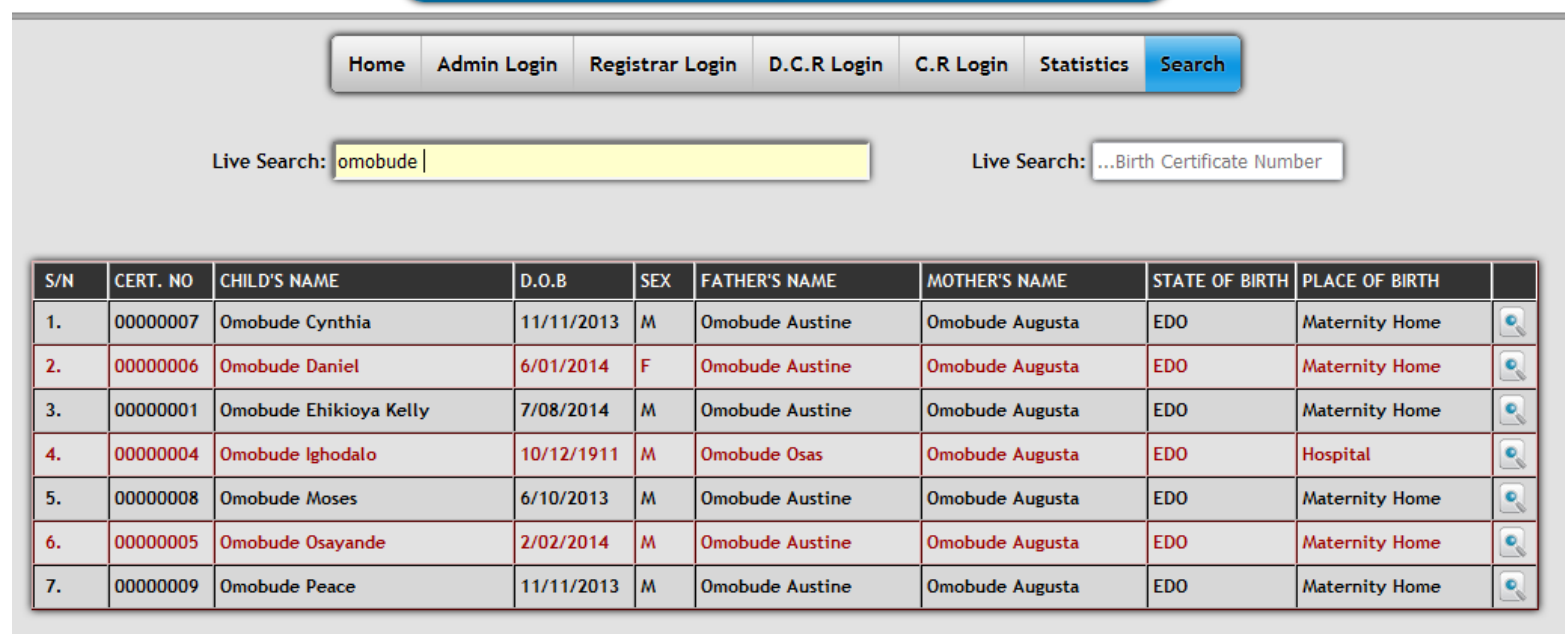

Figure 4: Online Birth Verification Query Result by Citizen Name

\section{RESULTS AND DISCUSSION}

An interactive functional prototype of the Nigerian civil birth registration and records system that could address the aforementioned challenges of the present Nigerian CRVS system was realized. The system consisted of birth information repository and several modules collectively to meet users' need and NPC's objectives. Thus, the system's search module was specifically tested to verify birth information of some citizens using name or birth registration number as captured in Figure 4 and Figure 5.

Figure 4 shows the citizens with surname "Omobude" in the system. Here, it is possible to identify possible duplication of individual citizen's record which may not have been detected at registration or entry point. Any birth information can be checked to checkmate falsification irrespective of its registration centre. 


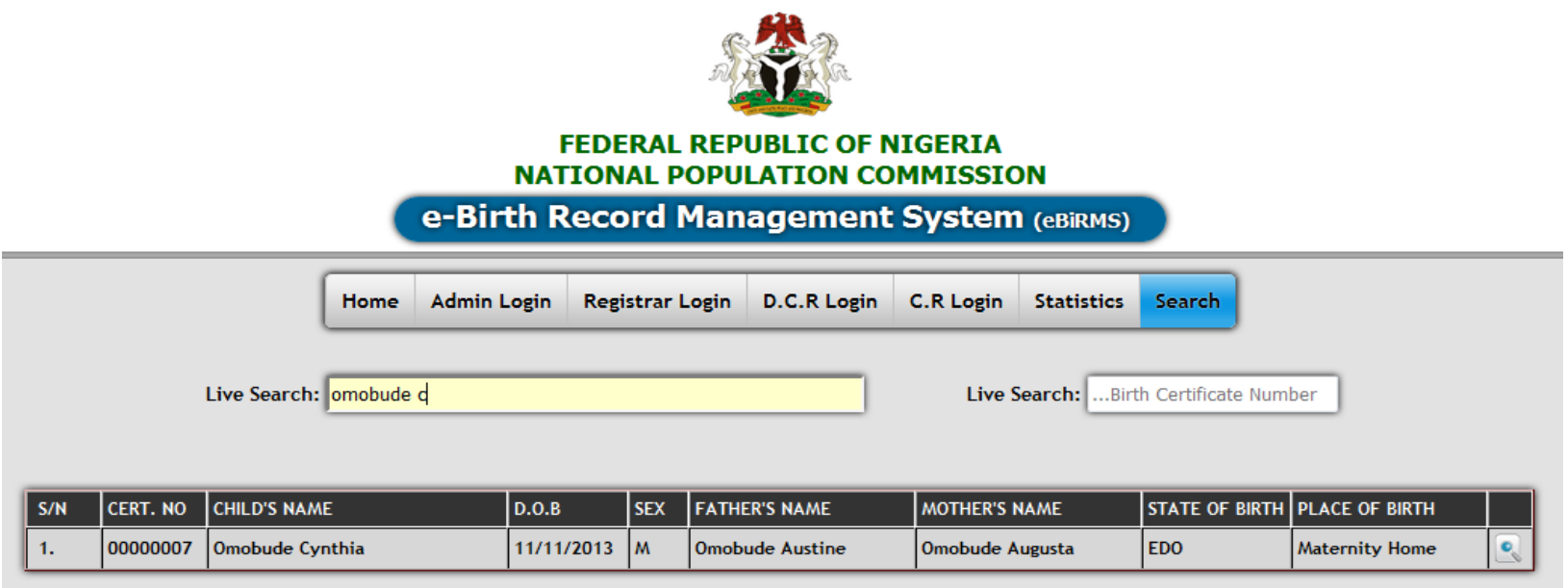

Figure 5: Online Birth Verification Query Result by Citizen Complete Name

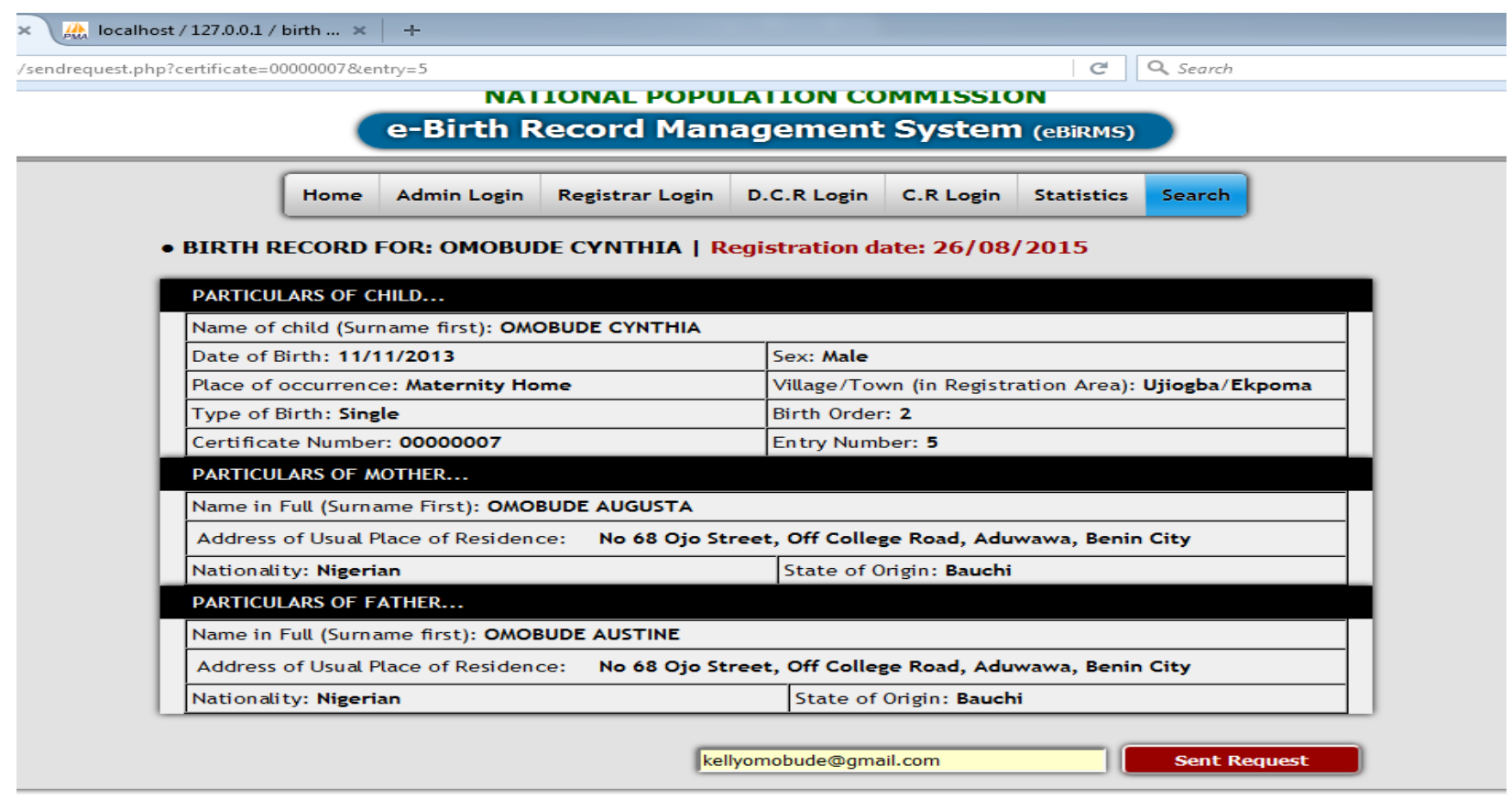

Figure 6: Detail Birth Information of Citizen "Omobude Cynthia".

Figure 5 shows the citizens with "Omobude Cynthia" in the system. Observe that even "Cynthia" was yet to be entered completely for "Omobude Cynthia" birth record to be displayed since no other "Omobude" in the system is with first name starting with " $\mathrm{C}$ ". If the search data does not exist, no record will be displayed. Details of "Omobude Cynthia" was then queried by clicking on the query button on the right cell of the citizen's record; and captured in Figure 6.A collection of related birth information is warehoused in a repository to make retrieval of information feasible and swift as against the rigorous processes of having to locate the registration centre with bulk of files to go through.

\section{CONCLUSION}

This research exposed the limitations of the present Nigerian civil birth registration and record management system. It developed a prototype electronic Birth Record Management system. The designed and implemented system allows for instant verification of individual birth record of Nigerians and is capable of checking the challenges which include alteration, theft, destruction, duplication and falsification associated with birth information. On full deployment, this system will therefore, curb the falsification of birth information in Nigeria. 


\section{REFERENCES}

[1] UNICEF (2011), "Accelerating Birth Registration in Sub-Saharan Africa", Support for the Rabat Process on Migration and Development, Meeting of Experts on Civil Registry, Warsaw, Poland, 32pp.

[2] Ahsan, K. Z., Jamil, K., Nahar, Q., Arifeen, S. E., Hill, K. and Streatfield, P. K. (2014), "Maternal Mortality in Bangladesh: a Countdown to 2015 Country Case Study", The Lancet. Vol. 384, 1366 pp.

[3] Akande, T. M. and Sekoni, S. O. (2005), "A Survey on Birth and Death Registration in a Semi-Urban Settlement in Middle-Belt Nigeria", European Journal of Scientific Research, Vol 8. pp. 56 - 61.

[4] UNICEF (2005), "The 'Rights' Start to Life: A Statistical Analysis of Birth Registration", United Nations Children's Fund, New York, USA, 35 pp.

[5] UNICEF (2013), "A Passport to Protection: A Guide to Birth Registration Programming", United Nations Children's Fund, New York, USA, 164 pp.

[6] UNICEF (2014), "Birth Registration in Bangladesh", Factsheet, United Nations Children's Fund, Bangladesh, 3pp.

[7] Akinyemi, J. O. and Adebowale, A. S. (2011), "Revamping the Civil Registration and Vital Statistics in Nigeria" Sixth African Population Conference. Union for African Population Studies (UEPA). 4 pp.
[8] Brown, J. G. (1998), "Birth Certificate Fraud", Department of Health and Human Services, Office of the Inspector General, Kansas City, 37pp.

[9] Brown, J. G. (2000), "Birth Certificate Fraud", Department of Health and Human Services, Office of the Inspector General, Kansas City, 31pp.

[10] Aplan, K., Blitz, B. K., Hamilton, C., Lagaay M., Lakshman, R. and Yarrow, E. (2014), "Birth Registration and Children's Right: A Complex Story", Plan International, United Kingdom, 147 pp.

[11] NPC, (2008), "Report of Live births, Deaths and Stillbirths in Nigeria", National Population Commission, Abuja, Nigeria, 111 pp.

[12] Oladiji, S., Zubema, J. and Wakil, B. (2013), "Monitoring of CRVS Operations in Nigeria (Successful Practice)", Retrieved online at: http://www.uneca.org/sites/default/files/images/ monitoring-of-vrs-in-nigeria_durbanpresentation.pdf, on 26/10/2015.

[13] Oliha, F. O. (2012), "A Segmentation System for Electronic Customer Relationship Management (eCRM); Case Study: 'Internet Service Users'"', M.Sc. Thesis, Computer Science Department, University of Benin, Nigeria, $98 \mathrm{pp}$.

[14] Generis, S. (2006), "Data Flow Diagram Process" San Jose University, Retrieved online at http://www.engr.sjsu.edu/ fayad/current.courses /cmpe202-fall07/docs/projects/Sample-Process2.pdf, on $26 / 10 / 2015$. 